\title{
Effects of selenium supplementation on chemical composition and aromatic profiles of cow milk and its derived cheese
}

\author{
Andrea lanni, ${ }^{1}$ Francesca Bennato, ${ }^{1}$ Camillo Martino, ${ }^{2}$ Denise Innosa, ${ }^{1}$ Lisa Grotta, ${ }^{1}$ and Giuseppe Martino ${ }^{1 *}$ \\ ${ }^{1}$ Faculty of BioScience and Technology for Food, Agriculture and Environment, University of Teramo, Italy 64100 \\ ${ }^{2}$ Department of Veterinary Medicine, University of Perugia, Italy 06126
}

\section{ABSTRACT}

This study aimed to investigate the effect of dietary selenium supplementation of Friesian cows on chemicalnutritional and volatile fraction of caciocavallo cheese. A sample of 32 Friesian cows, balanced for parity, milk production, and days in milk, were randomly assigned to 2 groups. The control group (CG) was fed with a conventional feeding strategy, while the experimental group (SeG) received a daily selenomethionine supplementation of $0.45 \mathrm{mg} / \mathrm{kg}$ in total mixed ration. During the experimental period, milk yield was monitored, and samples of milk and caciocavallo cheese were collected and analyzed to obtain information on chemicalnutritional composition and volatile compounds profile. Dietary Se integration did not induce variations on milk yield or composition but significantly lowered the somatic cell count (SCC). In both milk and cheese, samples from SeG were characterized by a lower concentration of saturated fatty acids (SFA) and increases in linoleic and rumenic acids. The volatile compounds profile of dairy products was also positively affected by dietary Se intake, with an increase in concentration of free fatty acids, esters, and aldehydes. These results suggest that Se plays a positive role in improving bovine mammary gland functionality and the nutraceutical properties of milk and caciocavallo cheese made therefrom. Such findings could contribute to the production of cheeses with interesting organoleptic properties, although further sensorial evaluations should be performed to deeply investigate these changes and confirm consumer acceptability.

Key words: selenium, fatty acid, oxidative stability, volatile compound

Received January 27, 2019.

Accepted April 23, 2019.

*Corresponding author: gmartino@unite.it

\section{INTRODUCTION}

High-yielding dairy animals require feeding strategies that guarantee appropriate contribution of all necessary microelements, such as selenium, zinc, manganese, copper, cobalt, and iodine. As regards selenium (Se), its importance for mammals lies in the numerous biological functions it performs; examples include cellular response to oxidative stress, redox signaling, cellular differentiation, immune response, and protein folding (Steinbrenner et al., 2016). About 35 selenoproteins, with tissue-specific expression, have been identified, although the roles of many have not yet been fully elucidated (Rayman, 2000). Dietary Se deficiency in livestock leads to a wide range of disorders, especially associated with growth depression, inefficient feed utilization, lower production performance, and depressed immunocompetence that may increase animals' susceptibility to infectious diseases (Reffett et al., 1988).

Both veterinary and human medicine have placed considerable emphasis on research aimed at identifying food supplements to provide sufficient bioavailability of this important microelement. Se absorption results are much lower in ruminants than among nonruminants, and many dietary factors could influence the mechanisms involved. For instance, high dietary sulfur (Van Ryssen et al., 1998) and the presence of cyanogenetic glycosides in certain legumes were reported to reduce Se bioavailability, while feeding organic Se from selenomethionine (SeMet) or selenized yeast (SeY) results in much higher tissue and milk selenium concentrations (Spears, 2003). The predominant Se form that naturally occurs in feedstuffs is SeMet, and many studies report similar efficiency in Se absorption between SeMet and selenite. However, urinary excretion of Se was reported to be higher in lambs and goats fed selenite than in those fed SeMet (Aspila, 1991). By monitoring erythrocyte glutathione peroxidase activity, it has been determined that feeding selenite to Se-deficient heifers results in an approximately double Se bioavailability compared with feeding with SeMet or SeY (Pehrson et al., 1989). Gresakova et al. (2013) compared the effects of feed supplementation with equivalent Se doses from 
sodium selenite and $\mathrm{SeY}$ on Se absorption, retention, balance, and tissue deposition in lambs. The results demonstrated that feed supplementation with SeY results in higher absorption of Se from the digestive tract and greater body Se retention than does feed supplementation with selenite; however, the inorganic Se source, sodium selenite, was as effective as the organic $\mathrm{SeY}$ in supplying this essential trace element for the activity of glutathione peroxidase in blood. Moreover, $\mathrm{SeY}$ has also been reported to improve rumen fermentation, milk yields, and feed digestion in Holstein dairy cows. It has been suggested that SeY stimulates the enzymatic mechanisms mediated by digestive microorganisms in a dose-dependent manner (Wang et al., 2009).

Ruminal mechanisms directly contribute to the chemical-nutritional qualities of milk and related dairy products. In fact, ruminant products represent the only foods to contain CLA and significant amounts of several MUFA, which represent the only natural source of trans fatty acids (FA) in the human diet (Doreau et al., 2016). However, the effects of Se supplementation on the chemical-nutritional characteristics of milk and dairy products have received less attention. A few studies have reported that Se addition to ruminants' diets does not correspond with any variation in terms of milk yield or concentrations of fat, protein, or lactose (Givens et al., 2004; Calamari et al., 2010). In this context the study of Ran et al. (2010), in which Se supplementation of dairy cows induced a significant increase of PUFA in milk, is particularly interesting. The aim of the present study was to evaluate the effects of dietary SeMet supplementation on Friesian dairy cows, with particular attention to the nutritional quality, FA composition, oxidative stability, and aromatic profile of milk and caciocavallo cheese made from this milk.

\section{MATERIALS AND METHODS}

\section{Experimental Design, Diets, and Sampling}

The present experiment was performed according to Directive 2010/63/EU of the European Parliament (European Union, 2010) and Directive 86/609/ EEC (European Economic Community, 1986), which deal with the protection of animals used for scientific purposes. No animals were killed in the course of this study.

This study sampled 32 healthy Friesian cows, homogeneous for age $(41.5 \pm 2.5 \mathrm{mo})$ and lactation days $(76$ $\pm 14 \mathrm{~d}$ ). Animals were randomly divided into 2 groups of 16 cows each: a control group (CG) and an experimental group (SeG) whose diet was supplemented with SeMet. The study was conducted for a period of $63 \mathrm{~d}$,
Table 1. Ingredients and chemical composition of TMR administered to each animal of both study groups ${ }^{1}$

\begin{tabular}{lc}
\hline Item & Percentage \\
\hline Ingredients of TMR & \\
Corn silage & 23.8 \\
First-cut alfalfa hay & 5.2 \\
Corn meal & 3.6 \\
Soybean meal & 3.1 \\
Fine bran & 3.6 \\
Barley meal & 1.7 \\
CaCO & 0.2 \\
Vitamins and minerals & 0.5 \\
Chemical composition of TMR & \\
Total DM & 56.63 \\
CP & 15.31 \\
Ether extract & 2.99 \\
Ash & 5.29 \\
NDF & 32.61 \\
ADF & 20.19 \\
Starch & 26.93 \\
\hline
\end{tabular}

${ }^{1}$ Animals in study groups were fed $22.61 \mathrm{~kg}$ of DM/head per $\mathrm{d}$. Selenium was supplemented to the experimental group $(\mathrm{SeG})$ at a rate of $0.45 \mathrm{mg} / \mathrm{kg}$ of TMR.

${ }^{2} \mathrm{On}$ a DM basis.

in which animals of each experimental group were freehoused in 2 separate areas, with access to a shared feeding area. All animals received about $22 \mathrm{~kg}$ of DM per head daily of TMR, whose composition (Table 1) was defined taking into account the parameters reported in the seventh edition of Nutrient Requirements of Dairy Cattle (NRC, 2001). Samples of TMR were analyzed according to the methods prescribed by AOAC International (1990) for CP (method 930.15), ether extract (method 920.39), crude fiber (method 962.09), and ash (method 942.05); procedures reported by Van Soest et al. (1991) were used to determine levels of NDF and ADF.

During the entire experimental period, CG cows received a standard complete food formulated for the nutritional needs of cows in mid-lactation. The SeG cows received the same complete food, formulated according to the same requirements and prepared in the same way, but the daily ration of each cow was supplemented with $0.45 \mathrm{mg}$ of organic Se per $\mathrm{kg}$ of TMR. Current EU regulations have limited the use of organic Se supplementation to a maximum of $0.2 \mathrm{mg} /$ $\mathrm{kg}$ in complete feed, with overall content of Se in the feed not to exceed $0.5 \mathrm{mg} / \mathrm{kg}$. The ration was prepared using SeMet in the form of a crystalline powder that was incorporated into feed as a premixture, according to the recommendations reported in Regulation No. 121/2014 of the European Commission, concerning the authorization of L-selenomethionine as a feed additive for all animal species.

On d 63, milk was collected separately from each group, and the same procedures were followed for each 
group to obtain caciocavallo cheese, according to the following manufacturing protocol. The milk was first filtered into a tub and then pasteurized at $72 \pm 1.5^{\circ} \mathrm{C}$ for $3 \mathrm{~min}$. High-temperature short-time pasteurization was achieved using a pasteurization plant with integrated heat exchanger, de-aerator, homogenizer, and temperature control system. After cooling, milk was heated to 36 to $38^{\circ} \mathrm{C}$ and transferred to a container with starter bacteria (30 g/1000 L): Streptococcus thermophilus, Lactobacillus delbrueckii ssp. bulgaricus, and Lactobacillus helveticus (Dalton Biotecnologie S.r.l., Pescara, Italy). Calf rennet was then added to induce curd formation, with the amount used calculated according to rennet strength and milk acidity. Full coagulation required an additional 20 to $30 \mathrm{~min}$, at the end of which the curd texture was checked and curds were roughly broken up, removing part of the whey, followed by further breaking to obtain small clots that ensure a smoother paste more suitable for ripening. The mass is left in the whey for at least $2 \mathrm{~h}$ and then moved to another container with water at $80^{\circ} \mathrm{C}$, to facilitate stretching. Last, the cheeses were shaped by hand, tied at the top, and moved to a container of cold water for hardening. They were then soaked in brine for 12 to $20 \mathrm{~h}$. After salting, the cheeses were left to ripen at 10 to $15^{\circ} \mathrm{C}$, with a relative humidity of 85 to $90 \%$. To evaluate changes in chemical composition and quality attributes due to ripening, sampling and analyses on the cheeses were carried out after $7 \mathrm{~d}\left(\mathbf{T}_{7}\right)$ and $120 \mathrm{~d}$ $\left(\mathbf{T}_{120}\right)$ from the start of cheese-making. Samples, collected in triplicate from 3 different cheeses, were partly immediately analyzed and partly vacuum sealed and frozen at $-20^{\circ} \mathrm{C}$ until analysis.

\section{Chemical Analysis of Milk and Caciocavallo Cheese}

Chemical composition of milk (fat, protein, casein, lactose, and urea) was determined using a MilkoScan FT 6000 (Foss Integrator IMT; Foss A/S, Hillerød, Denmark), and SCC and total bacterial count were performed using the Fossomatic TM FC and the BactoScan FC (Foss A/S), respectively. In cheese, evaluations of $\mathrm{pH}$, dry matter, total proteins, lipids, and ash were performed as described by Tofalo et al. (2015).

Se contents of milk and cheese was determined via inductively coupled plasma MS, using an Agilent 7500ce (Agilent Technologies, Santa Clara, CA) and following the procedure reported by Gerber et al. (2009), with slight modifications. Samples, $5 \mathrm{~mL}$ of milk or $5 \mathrm{~g}$ of cheese, were inserted into quartz digestion vessels, and $3 \mathrm{~mL}$ of $30 \%$ hydrogen peroxide and $10 \mathrm{~mL} 65 \%$ nitric acid were added to each tube. The tubes were sealed for sample digestion at $95^{\circ} \mathrm{C}$ for $2 \mathrm{~h}$. After the vessels had cooled, the digests were transferred into $50-\mathrm{mL}$ volumetric flasks and filled to the mark using purified water. Of the resulting solution, $1 \mathrm{~mL}$ was combined with $9 \mathrm{~mL}$ of distilled nitric acid (1\%) and analyzed. Quantitative determinations were performed by referring to a calibration, and results were expressed in $\mu \mathrm{g} /$ $\mathrm{kg}$.

The milk lipid fraction was extracted according to the AOAC official method (AOAC International, 2000), and in cheese, extraction was performed as described by Domagała et al. (2010), using a mixture of chloroform and methanol (2:1, vol/vol). Transmethylation of lipid extracts and separation of FAME were performed following the procedure reported by Ianni et al. (2019a). Peak areas were quantified using ChromeCard software (Thermo Fisher Scientific, Waltham, MA), and the relative value of each individual FA was expressed as a percentage of the total FA. The value of each FA was used to calculate the sum of MUFA, PUFA, and SFA. Taking into account the values associated with each FA, atherogenic and thrombogenic indices were calculated in milk and cheese using the formulas proposed by Ulbricht and Southgate (1991); desaturation index was calculated as proposed by Mele et al. (2007).

\section{Evaluation of Lipid Oxidation in Cheese}

Fat oxidation was evaluated by measuring thiobarbituric acid reactive substances. The analysis was performed according to the procedure reported by Grotta et al. (2017), with slight modifications. For each sample, within 2 min of the sample being removed from the freezer, an aliquot of $4.5 \mathrm{~g}$ of frozen cheese was mixed with $450 \mu \mathrm{L}$ of $0.1 \%$ butylated hydroxytoluene in methanol, to stop the oxidation process. The mixture was homogenized with an Ultra Turrax T-25 highspeed homogenizer (IKA Werke, Staufen, Germany) in $45 \mathrm{~mL}$ of an aqueous solution of $7 \%$ trichloroacetic acid and then subjected to distillation. An aliquot of $2 \mathrm{~mL}$ of each distillate was mixed with an equal volume of a $0.02 M$ thiobarbituric acid (TBA) solution in $90 \%$ acetic acid. The solution was kept for $1 \mathrm{~h}$ in a thermostated bath at $80^{\circ} \mathrm{C}$ and, after cooling, was evaluated for absorbance with a spectrophotometer (Jenway, Essex, UK); the wavelength was set at $534 \mathrm{~nm}$. The amount of oxidized compounds of each sample was calculated using a calibration curve, and results were expressed in micrograms of malondialdehyde per gram of cheese.

\section{Volatile Compounds Extraction and GC-MS Analysis}

Extraction of volatile organic compounds (VOC) from milk and cheese samples was performed via solid- 
phase microextraction, and GC-MS analysis was performed using a gas chromatograph (Clarus 580; Perkin Elmer, Waltham, MA) coupled with a mass spectrometer (SQ8S; Perkin Elmer). The gas chromatograph was equipped with an Elite-5MS column (length $\times$ internal diameter: $30 \times 0.25 \mathrm{~mm}$; film thickness: 0.25 $\mu \mathrm{m}$; Perkin Elmer). We mixed $5 \mathrm{~g}$ of cheese (previously grated) with $10 \mathrm{~mL}$ of saturated $\mathrm{NaCl}$ solution (360 $\mathrm{g} / \mathrm{L})$, then added $10 \mu \mathrm{L}$ of internal standard solution (4-methyl-2-heptanone; $10 \mathrm{mg} / \mathrm{kg}$ in ethanol). The vials were sealed with a polytetrafluoroethylene-silicone septum (Supelco, Bellefonte, PA) and stirred at $60^{\circ} \mathrm{C}$; VOC were extracted from the headspace with a divinylbenzene-carboxen-polydimethylsiloxane solid-phase microextraction fiber (length: $1 \mathrm{~cm}$; film thickness: 50/30 $\mu \mathrm{m}$; Supelco) with an exposition time of $60 \mathrm{~min}$. After adsorption time, the extracted VOC were thermally desorbed into the GC injector in splitless mode for $1 \mathrm{~min}$ at $250^{\circ} \mathrm{C}$. The oven temperature was held at $50^{\circ} \mathrm{C}$ for $1 \mathrm{~min}$, increased at a rate of $3^{\circ} \mathrm{C} / \mathrm{min}$ up to $200^{\circ} \mathrm{C}$ and held for $1 \mathrm{~min}$, and then increased from $200^{\circ} \mathrm{C}$ to $250^{\circ} \mathrm{C}$ at $1^{\circ} \mathrm{C} / \mathrm{min}$ and held for $15 \mathrm{~min}$. Helium was used as a carrier gas at a flow rate of $1 \mathrm{~mL} / \mathrm{min}$. The mass spectrometer operated in electronic impact ionization mode at $70 \mathrm{eV}$, and data were collected in full scan mode, with a scan time of $0.2 \mathrm{~s}$ over a mass range of 35 to 350 . Source and interface temperature were held at $250^{\circ} \mathrm{C}$. Identification of VOC was achieved by comparing mass spectra of individual compounds to those in the NIST library using NIST Mass Spectral Search Program (version 2.0; National Institute of Standards and Technology, Gaithersburg, MD) and comparing the eluting order with Kovats indices. Samples were analyzed in triplicate, and quantification was carried out integrating the peak areas of a target ion for each compound.

\section{Statistical Analysis}

Milk yield and chemical composition were analyzed according to a mixed model using PROC MIXED of SAS (version 9.0; SAS Institute Inc., Cary, NC), with diet and period as fixed factors. The FA compositions of individual milk samples collected on the last day of the trial were analyzed according to PROC MIXED, with diet as a fixed effect plus cows nested within treatment. Chemical and FA composition and aromatic profiles of cheese were analyzed by PROC GLM, including diet and time of ripening as fixed effects. Separation of means was considered significant for $P<0.05$.

\section{RESULTS}

\section{Chemical-Nutritional Composition of Milk and Cheese}

Dietary Se supplementation did not affect milk production over the $63 \mathrm{~d}$ of the trial; no significant differences were evidenced between the 2 experimental groups. Analysis of the chemical-nutritional characteristics of milk also did not show significant variations (Table 2). Specifically, the experimental diet administered to the cows did not induce quantitative changes in total fat, proteins, caseins, lactose, or urea; in the same way, no changes in $\mathrm{pH}$ were found. However, the diet enriched with Se showed a marked and significant reduction of SCC $(208 \pm 15$, vs. $153 \pm 11$ cells $/ \mathrm{mL}$ $\times 10^{3}$ in $\mathrm{CG}$ and SeG, respectively; $P<0.05$ ). Total bacterial count was also reduced in milk samples from SeG, although this variation was not significant $(38 \pm$ 7 , vs. $31 \pm 5 \mathrm{cfu} / \mathrm{mL} \times 10^{3}$ in $\mathrm{CG}$ and SeG, respectively; $P>0.05$ ). Significantly higher average levels of Se were found in milk samples from SeG (20.21 \pm

Table 2. Milk yield and chemical composition of milk obtained from the control group (CG) and the experimental group (SeG)

\begin{tabular}{lccc}
\hline & \multicolumn{2}{c}{ Diet } & \\
\cline { 2 - 3 } Variable & CG & SeG & $P$-value \\
\cline { 2 - 3 } Milk yield (kg) & $37.15 \pm 2.26$ & $39.63 \pm 3.01$ & NS \\
Composition & $3.47 \pm 0.31$ & $3.01 \pm 0.27$ & NS \\
$\quad$ Fat $(\%)$ & $3.11 \pm 0.26$ & $3.10 \pm 0.29$ & NS \\
Protein $(\%)$ & $2.40 \pm 0.18$ & $2.41 \pm 0.21$ & NS \\
Casein $(\%)$ & $4.67 \pm 0.40$ & $4.73 \pm 0.24$ & NS \\
Lactose $(\%)$ & $20.88 \pm 1.51$ & $21.10 \pm 1.42$ & NS \\
Urea $(\mathrm{mg} / 100 \mathrm{~mL})$ & $208.0 \pm 15.0$ & $153.0 \pm 11.0$ & $*$ \\
SCC $\left(\times 10^{3}\right.$ cells $\left./ \mathrm{mL}\right)$ & $38.0 \pm 7.0$ & $31.0 \pm 5.0$ & $\mathrm{NS}$ \\
Total bacterial count $\left(\times 10^{3} \mathrm{cfu} / \mathrm{mL}\right)$ & $6.51 \pm 0.07$ & $6.50 \pm 0.06$ & $\mathrm{NS}$ \\
pH & $39.0 \pm 1.17$ & $49.46 \pm 3.32$ & $* *$ \\
Se $(\mu \mathrm{g} / \mathrm{kg})$ & & & \\
$* P<0.05 ; * * P<0.01$ & & &
\end{tabular}


Table 3. Chemical composition of cheese obtained from the control group (CG) and the experimental group (SeG), analyzed at $7\left(\mathrm{~T}_{7}\right)$ and $120\left(\mathrm{~T}_{120}\right)$ d after cheese-making

\begin{tabular}{|c|c|c|c|c|}
\hline \multirow[b]{2}{*}{ Item } & \multicolumn{2}{|c|}{$\mathrm{T}_{7}$} & \multicolumn{2}{|c|}{$\mathrm{T}_{120}$} \\
\hline & $\mathrm{CG}$ & $\mathrm{SeG}$ & $\mathrm{CG}$ & $\mathrm{SeG}$ \\
\hline$\overline{\mathrm{DM}}(\%)$ & $54.91^{\mathrm{A}} \pm 3.71$ & $53.21^{\mathrm{A}} \pm 4.32$ & $66.57^{\mathrm{B}} \pm 3.86$ & $65.12^{\mathrm{B}} \pm 4.14$ \\
\hline Fat $^{1}(\%)$ & $39.37 \pm 2.92$ & $41.15 \pm 3.22$ & $37.74 \pm 3.31$ & $37.96 \pm 2.83$ \\
\hline Protein $(\%)$ & $54.18 \pm 3.78$ & $50.17 \pm 2.92$ & $49.58 \pm 3.42$ & $49.03 \pm 3.61$ \\
\hline $\operatorname{Ash}^{1}(\%)$ & $4.43 \pm 0.34$ & $5.24 \pm 0.52$ & $5.62 \pm 0.49$ & $6.02 \pm 0.57$ \\
\hline $\mathrm{Se}(\mu \mathrm{g} / \mathrm{kg})$ & $208.0^{\mathrm{a}} \pm 9.2$ & $290.0^{\mathrm{b}} \pm 10.4$ & $193.0^{\mathrm{a}} \pm 5.7$ & $306.0^{b} \pm 7.9$ \\
\hline
\end{tabular}

1.17 , vs. $49.46 \pm 3.32 \mathrm{mg}$ of $\mathrm{Se} / \mathrm{kg}$ in $\mathrm{CG}$ and $\mathrm{SeG}$, respectively; $P<0.01$ ).

Similarly to milk, diet supplementation did not affect the chemical composition of cheese in terms of total fat, proteins, or ash (Table 3), but an increase of Se content in SeG was found in both $\mathrm{T}_{7}$ and $\mathrm{T}_{120}$ samples $(P<0.01)$. Taking into account the ripening time, as expected, dry matter levels were significantly higher in $\mathrm{T}_{120}$ samples than in $\mathrm{T}_{7}$ samples $(66.57 \%$ vs. $54.91 \%$ in CG, and $65.12 \%$ vs. $53.51 \%$ in SeG samples; $P<0.01$ ).
Fatty Acid Profile and Oxidative Stability of Cheese

The FA profile of milk and corresponding dairy products is reported in Table 4. Samples of bulk milk obtained from SeG evidenced increased content of myristoleic acid (C14:1; $P<0.05)$, linoleic acid (C18:2; $P<0.05$ ), and rumenic acid (CLA cis-9 trans-11; $P$ $<0.05)$; however, total SFA was reduced $(P<0.05)$. For the cheese samples, changes were already evident in milk, with increases in SeG concentration, linoleic

Table 4. Fatty acid profile of bulk milk and cheeses obtained from the control group (CG) and the experimental group (SeG) ${ }^{1}$

\begin{tabular}{|c|c|c|c|c|c|c|}
\hline Item & \multicolumn{3}{|c|}{ Milk } & \multicolumn{3}{|c|}{ Cheese } \\
\hline C12:0 & $3.99 \pm 0.31$ & $3.87 \pm 0.32$ & NS & $4.13 \pm 0.34$ & $3.96 \pm 0.29$ & NS \\
\hline C14:0 & $12.88 \pm 1.05$ & $12.22 \pm 1.12$ & NS & $12.56 \pm 0.98$ & $12.06 \pm 1.07$ & NS \\
\hline C14:1 & $0.46 \pm 0.05$ & $0.68 \pm 0.06$ & $*$ & $0.73 \pm 0.06$ & $0.81 \pm 0.07$ & NS \\
\hline C15:0 & $1.23 \pm 0.11$ & $1.18 \pm 0.08$ & NS & $1.51 \pm 0.12$ & $1.53 \pm 0.13$ & NS \\
\hline $\mathrm{C} 17: 0$ & $0.55 \pm 0.05$ & $0.52 \pm 0.05$ & NS & $0.58 \pm 0.06$ & $0.56 \pm 0.05$ & NS \\
\hline C18:0 & $8.72 \pm 0.74$ & $7.91 \pm 0.71$ & NS & $9.20 \pm 0.81$ & $9.19 \pm 0.72$ & NS \\
\hline C18:1 trans-11 & $0.68 \pm 0.06$ & $0.73 \pm 0.06$ & NS & $0.58 \pm 0.06$ & $0.53 \pm 0.05$ & NS \\
\hline $\mathrm{C} 18: 1$ cis-9 & $15.95 \pm 1.02$ & $17.43 \pm 1.13$ & NS & $15.41 \pm 1.21$ & $15.64 \pm 0.97$ & NS \\
\hline C18:1 cis-11 & $0.38 \pm 0.04$ & $0.45 \pm 0.04$ & NS & $0.45 \pm 0.04$ & $0.53 \pm 0.05$ & NS \\
\hline C18:2 & $1.83 \pm 0.16$ & $2.21 \pm 0.18$ & $*$ & $1.96 \pm 0.21$ & $2.46 \pm 0.16$ & $*$ \\
\hline C18:3 & $0.46 \pm 0.05$ & $0.52 \pm 0.05$ & NS & $0.64 \pm 0.06$ & $0.55 \pm 0.05$ & NS \\
\hline Atherogenic index ${ }^{3}$ & $4.20 \pm 0.29$ & $3.62 \pm 0.24$ & ** & $4.17 \pm 0.18$ & $3.84 \pm 0.11$ & $*$ \\
\hline Thrombogenic index ${ }^{3}$ & $4.77 \pm 0.36$ & $4.06 \pm 0.31$ & $*$ & $4.58 \pm 0.24$ & $4.38 \pm 0.22$ & NS \\
\hline Desaturation index ${ }^{3}$ & $0.03 \pm 0.00$ & $0.05 \pm 0.00$ & $*$ & $0.05 \pm 0.00$ & $0.06 \pm 0.00$ & NS \\
\hline
\end{tabular}

${ }^{1}$ Individual fatty acids (FA) are expressed as percent of total FA. Data are reported as mean (\%) \pm SD.

${ }^{2} \mathrm{CLA}$ cis- 9 , trans- $11=$ rumenic acid.

${ }^{3}$ Atherogenic index: $(\mathrm{C} 12: 0+4 \cdot \mathrm{C} 14: 0+\mathrm{C} 16: 0) /[\Sigma$ MUFA $+\Sigma$ PUFA (n-3; n-6)]. Thrombogenic index: $(\mathrm{C} 14: 0+\mathrm{C} 16: 0+\mathrm{C} 18: 0) /\{[0.5 \cdot \Sigma$ MUFA $]+[0.5 \cdot \Sigma$ PUFA (n-6) $]+[3 \cdot \Sigma$ PUFA (n-3) $]+(\mathrm{n}-3 / \mathrm{n}-6)\}$. Desaturation index: $(\mathrm{C} 14: 1$ cis-9)/(C14:0 + C14:1 cis-9).

${ }^{*} P<0.05 ; * * P<0.01$ 


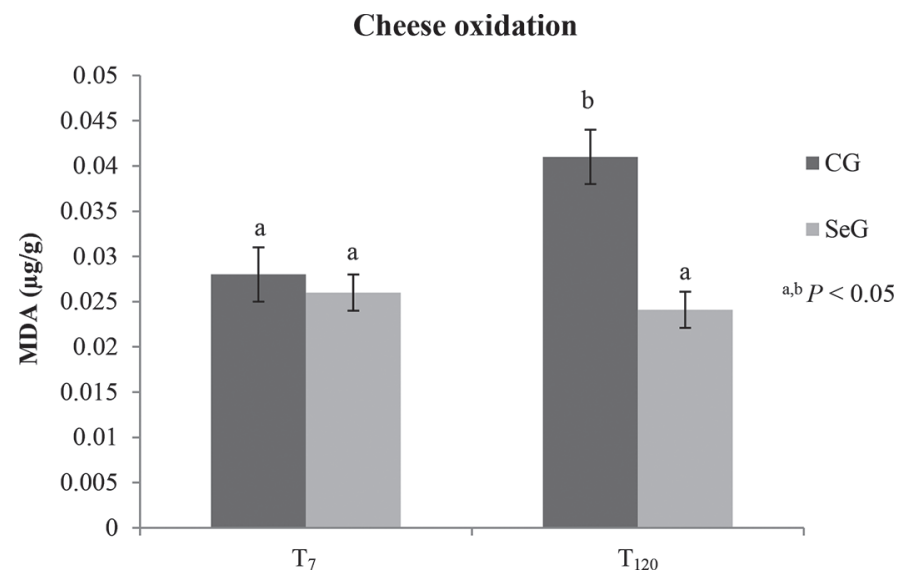

Figure 1. Lipid oxidation in caciocavallo cheese samples obtained from the control group (CG) and the experimental group (SeG), measured in terms of malondialdehyde (MDA) levels. Analyses were performed on samples obtained after $7\left(\mathrm{~T}_{7}\right)$ and $120 \mathrm{~d}\left(\mathrm{~T}_{120}\right)$ from cheesemaking. Letters $(\mathrm{a}, \mathrm{b})$ indicate significant differences $(P<0.05)$. Error bars represent SD.

acid (C18:2; $P<0.05)$, and rumenic acid (CLA cis-9 trans-11; $P<0.05)$. Taking into account the FA profile, calculations of atherogenic, thrombogenic, and desaturation indices were performed. In milk, SeG samples were characterized by reduction of both atherogenic and thrombogenic indices $(P<0.01$ and $P<0.05$, respectively), and an increase of the desaturation index was observed $(P<0.05)$. In cheese the only significant variation was evidenced for the atherogenic index, which decreased in SeG samples $(P<0.05)$.

One interesting finding is certainly due to the determination of the oxidative stability of cheese after 7 and $120 \mathrm{~d}$ of ripening. As shown in Figure 1, levels of oxidized compounds significantly increased in CG samples after $120 \mathrm{~d}$ (0.028 vs. $0.041 \mu \mathrm{g}$ malondialdehyde/g; $P<0.01$ ), whereas in SeG samples the data remained almost identical over time (0.026 vs. $0.024 \mu \mathrm{g}$ malondialdehyde/g; $P>0.05)$. It is important to consider that, at the beginning of ripening, the amount of oxidation products were similar between the 2 groups.

\section{Aromatic Profile of Cheese}

Analysis of VOC in $\mathrm{T}_{7}$ and $\mathrm{T}_{120}$ cheese samples obtained from $\mathrm{CG}$ and $\mathrm{SeG}$ allowed identification of several chemical families. The most represented compounds were free fatty acids (FFA), followed by methyl ketones, methyl esters, ethyl esters, lactones, aldehydes, and alcohols, testifying the prevalence of lipolytic catabolism with respect to the proteolytic event. For total FFA (Figure 2), the results obtained at $\mathrm{T}_{7}$ showed comparable levels between $\mathrm{CG}$ and $\mathrm{SeG}$ samples. In SeG samples for $T_{120}$, there was a marked increase of FFA, which reached significantly higher levels than those of CG samples $(P<0.01)$. It is also interesting to highlight the general increase of FFA in $\mathrm{T}_{120}$ samples, compared with $\mathrm{T}_{7}$ samples $(P<0.01)$ : FFA are about 1.85 times higher for $\mathrm{CG}$ at $\mathrm{T}_{120}$ and 2.95 times higher for $\mathrm{SeG}$ $\mathrm{T}_{120}$. Analysis of individual FFA showed variations only in $\mathrm{T}_{120}$ samples, with a significant increase of heptanoic $(P<0.05)$, octanoic $(P<0.01)$, and nonanoic $(P<$ $0.05)$ acids in SeG.

For other listed families of compounds (Table 5), several variations were evident at both $T_{7}$ and $T_{120}$. Methyl ketones showed higher concentrations of 2-pentanone in SeG in both $\mathrm{T}_{7}$ and $\mathrm{T}_{120}$ samples $(P<0.01)$; 2 -nonan-2-one was detected only in $\mathrm{T}_{120}$ samples, with higher concentration in SeG $(P<0.01)$; whereas 2 -tridecanone was identified only in $\mathrm{T}_{7}$ samples and was more represented in CG $(P<0.05)$. Dietary Se supplementation markedly influenced ester composition. In $\mathrm{T}_{7}$ samples from SeG, there was a significant increase of all methyl esters (shown in in Table 5) and a general decrease of ethyl ester concentration. In $\mathrm{T}_{120}$ cheese, the observed behavior was quite different: in the methyl esters group, only methyl hexanoate was lower $(P<$ 0.01) in SeG samples, whereas among the ethyl esters, there were higher concentrations of ethyl octanoate $(P$ $<0.05)$, ethyl decanoate $(P<0.01)$, ethyl tetradecanoate $(P<0.05)$, and ethyl hexadecanoate $(P<0.05)$, and lower concentrations for ethyl butanoate $(P<$ $0.05)$ and ethyl hexanoate $(P<0.01)$. Lactones were globally less represented in $\mathrm{T}_{7} \mathrm{SeG}$ samples, whereas no significant differences were detected in $\mathrm{T}_{120}$. Last, in both $\mathrm{T}_{7}$ and $\mathrm{T}_{120}$ samples, SeG samples also showed an increase of aldehydes (hexanal and heptanal) and a decrease of alcohols (1-hexanol and 1-octanol).

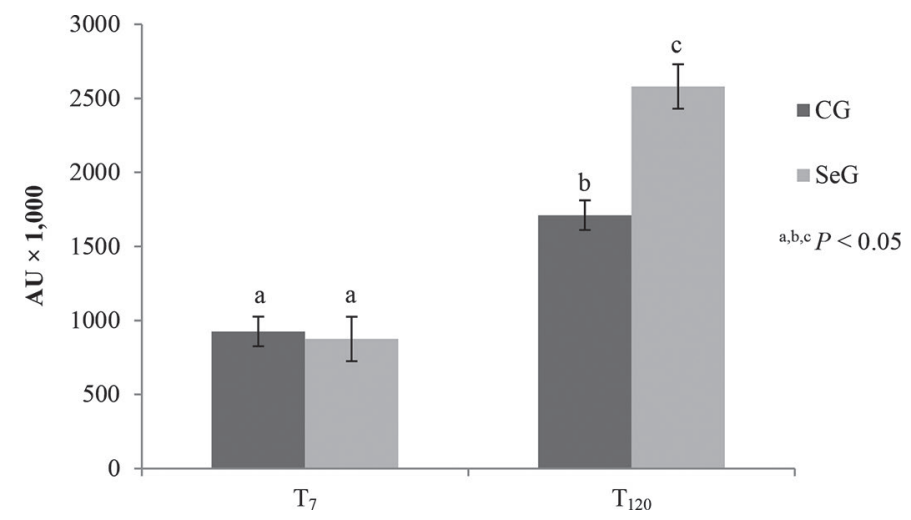

Figure 2. Free fatty acids (FFA) detected in caciocavallo cheese samples obtained from control group $(\mathrm{CG})$ and experimental group (SeG) after $7\left(\mathrm{~T}_{7}\right)$ and $120\left(\mathrm{~T}_{120}\right)$ d from cheese-making, measured in arbitrary units $(\mathrm{AU}) \times 1,000$. Letters $(\mathrm{a}-\mathrm{c})$ indicate significant differences $(P<0.05)$. Error bars represent SD. 


\section{DISCUSSION}

Dietary Se supplementation did not affect milk production or composition during the entire period of the trial. This finding is consistent with data previously reported by other authors who have tested the effect of different dietary Se forms and concentrations in dairy cows (Calamari et al., 2010; Givens et al., 2004). The results of the current study support the general view that dietary Se supplementation is unlikely to markedly affect either milk yield or milk composition in terms of fat, protein, or lactose. In accord with observations in milk, no differences were evidenced in the chemicalnutritional composition of cheese samples, in relation to either the feeding strategy or the ripening time. As expected, the only differences involved the increase in dry matter at the end of the ripening period.
An interesting result, obtained from analysis of milk samples, is the marked reduction in SCC for SeG. Kruze et al. (2007) reported that Se supplementation in dairy cows resulted in increased blood activity of glutathione peroxidase and lower mean SCC after an intramammary challenge with Staphylococcus aureus. Cortinhas et al. (2010) observed comparable results in dairy cows fed with organic Se, also recording fewer new and total cases of subclinical mastitis, without significant variations in concentration of antioxidant enzymes (superoxide dismutase, glutathione peroxidase, and ceruloplasmin). Other studies confirmed the potential of Se to enhance the humoral immune defense in the bovine mammary gland (Salman et al., 2009).

A result meriting special attention concerns the Se content, which increased in concentration in both milk and cheese samples obtained from SeG, confirming

Table 5. Volatile organic compounds (VOC) detected in cheese obtained from the control group (CG) and the experimental group (SeG), analyzed at $7\left(\mathrm{~T}_{7}\right)$ and $120\left(\mathrm{~T}_{120}\right)$ d after cheese-making ${ }^{1}$

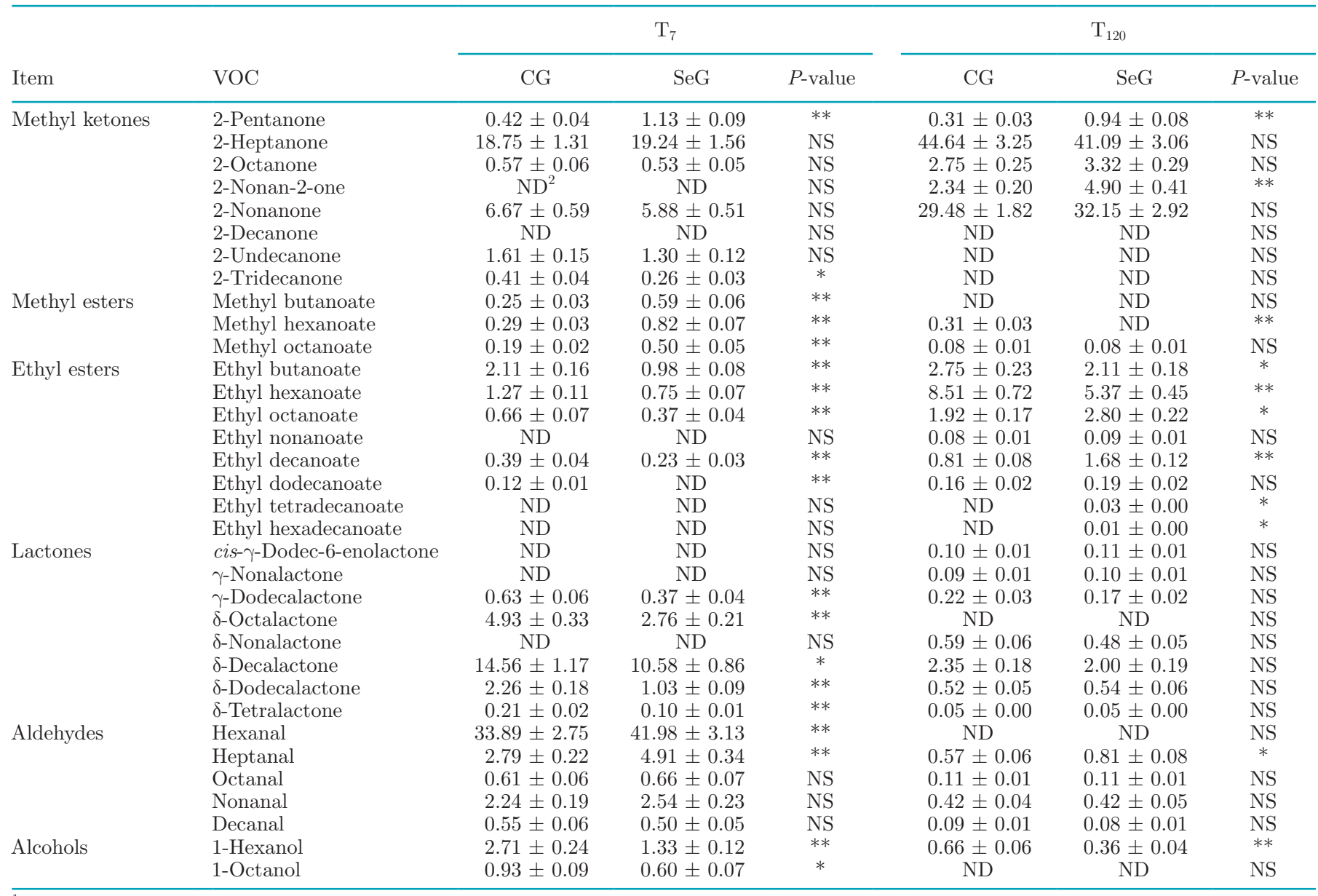

${ }^{1}$ Individual VOC are expressed as percent of total VOC. Data are reported as mean (\%) \pm SD.

${ }^{2} \mathrm{ND}=$ not detectable.

${ }^{*} P<0.05 ; * * P<0.01$. 
data previously reported by several studies (Ling et al., 2017; Calamari et al., 2010). Regarding cheese, Ling et al. (2017) also highlighted the role of the protein component in determining the transfer coefficient of Se from milk to the dairy product. From this point of view, in the present study, the increase of Se in the "experimental" cheese is not associated with a significant increase of the protein amount, suggesting that amount of protein may not be solely responsible for the observed phenomenon.

Dietary Se positively affected the levels of myristoleic and linoleic acids, as well as CLA in milk, and increased only linoleic acid and CLA in cheese. Because the diet administered to SeG did not confer an additional source of myristoleic acid compared with the CG diet, this result might be mainly related to the desaturation of myristic acid by stearoyl coenzyme A desaturase, a finding also supported by the $\mathrm{C} 14: 1 / \mathrm{C} 14: 0$ ratio, considered an index of $\Delta^{9}$ desaturation in the mammary gland (Mele et al., 2007). This endoplasmic reticulum-bound enzyme catalyzes the $\Delta^{9}$ desaturation of saturated fatty acyl-CoA (Miyazaki and Ntambi, 2003) and is encoded by the stearoyl coenzyme A desaturase gene (Smith et al., 2006), whose expression is regulated by the sterol regulatory element-binding protein. As reported by Pepper et al. (2011), Se has been shown to influence the expression of sterol regulatory element-binding protein in murine models, through a mechanism involving the expression of glutathione peroxidase; in ruminants this evidence needs further investigation. Dietary Se supplementation seems to lead also to increased CLA in milk and cheese. It is reported that CLA performs important antioxidant activity, which protects bovine mammary epithelial cells from lipoperoxidation and mitigates the levels of reactive oxygen species, leading to improvement of mammary gland function (Basiricò et al., 2015 and 2017). Ruminant products also represent the primary dietary source of CLA for humans. Several benefits of CLA for human health have been reported, and some important examples concern modulation of the immune system (Song et al., 2005), reduction of body fat accumulation (Evans et al., 2002), enhancement of bone mineralization (Platt et al., 2007), and potentially slowing the development of atherosclerosis (Lock et al., 2004). Finally, MUFA and PUFA content increased in milk and cheese obtained after feeding with zinc supplementation, at the expense of SFA. As a direct consequence of the SFA reduction, atherogenic and thrombogenic indices decreased in milk samples obtained from SeG, whereas in cheese only reduction of the atherogenic index was observed. In light of this, it could be argued that dietary Se supplementation may increase the nutritional value and health functionality of milk and related dairy products.
Evaluation of TBA-reactive substances was used in this study as a marker for oxidative damage in cheese. Selenium has been reported to play an important role in reactive oxygen-based radicals scavenging, with a direct effect of opposing lipid peroxidation in biological systems (Zimmerman et al., 2015). The TBA values of cheese obtained at $\mathrm{T}_{7}$ from both $\mathrm{CG}$ and $\mathrm{SeG}$ were similar. However, in $\mathrm{T}_{120}$ samples, TBA values increased, as expected, in CG cheese, whereas SeG cheese samples maintained values comparable to those at $T_{7}$, suggesting antioxidant protection provided by Se. This finding is in agreement with the results obtained by Ling et al. (2017), who observed a marked reduction of oxylipins during ripening of cheese prepared using milk collected from cows fed with organic Se. The feeding strategy based on the use of inorganic Se led to a cheese with higher concentrations of oxidized compounds, although this concentration was still lower than that found in samples from the untreated group.

Evaluation of the aromatic profile of caciocavallo cheese allowed us to identify several classes of compounds, mostly derived from the lypolitic process; dietary influence on the aromatic profile of milk and derived dairy products has been recently reported (Castellani et al., 2017; Ianni et al., 2019b). The most represented class of VOC are FFA, which are also reported to be mainly responsible for the determination of cheese flavor, giving rise to cheesy, rancid, and sweaty odors. The increased FFA in SeG cheese samples could probably be explained by increased lipolysis of triglycerides by microbial and endogenous milk enzymes with Se supplementation, resulting in augmented release of FFA (Bertuzzi et al., 2018). The general increase of carboxylic acids in ripened cheese $\left(T_{120}\right)$ could be explained by the extent of starter cell autolysis, with the consequent release of peptidases, and especially lipases, that accelerate the lipolytic event (Collins et al., 2003). Not only do FFA directly contribute to the formation of cheese flavor, they also give rise to methyl ketones, aldehydes, lactones, and esters, which, in our study, seem to be influenced by dietary Se supplementation. Ketones may originate from FFA oxidation to $\beta$-ketoacids and their subsequent decarboxylation. Biosynthesis of methyl ketones is mainly attributed to mold metabolism, and the accumulation of methyl ketones is responsible for the typical odors with low perception thresholds, which characterize surface-moldripened and blue-veined cheeses (Collins et al., 2003). The increased concentrations of methyl ketones in SeG cheese samples at $T_{120}$ could derive from the effects of Se in favoring the enzymatic mechanisms that oversee their synthesis.

Esters are particularly represented in all cheese samples, but they tended to increase in concentration 
in SeG cheeses at the end of the ripening period. These compounds are characterized by a low odor threshold and are generally associated with the sweet, fruity, and floral notes of surface-ripened cheese flavors (Niimi et al., 2015).

No variations among lactones in cheeses were evidenced at $\mathrm{T}_{120}$ between the 2 study groups. Lactones are generally produced by a 1-step transesterification reaction of hydroxylated FFA. Hydroxylated FFA are released by lipolytic activities or by a heating process, but they can also be produced from catabolism of unsaturated FA, through the action of microbial lipoxygenases and hydratases (Bertuzzi et al., 2018). Probably dietary Se supplementation did not influence such enzymatic mechanisms compared with eventually existent in CG samples.

Regarding aldehydes, an increase in heptanal concentration both in $\mathrm{T}_{7}$ and $\mathrm{T}_{120}$ SeG cheese samples was observed. Heptanal, in combination with other aldehydes, is responsible for the "green, grasslike" aromas of cheeses, characterized by green, slightly fruity, lemon, and herbal notes (Bertuzzi et al., 2018). Alcohols are the least represented compounds in cheese samples analyzed in this study. Generally in surface-ripened cheeses, alcohols are the volatile compounds detected in highest numbers, compared with other classes of compounds. For that reason, the synthesis mechanisms and contributions of alcohols to the creation of cheeses' aromatic profiles deserve further evaluation.

\section{CONCLUSIONS}

The results of our study suggest a positive role of dietary Se supplementation in improving the nutritional and nutraceutical properties of cow milk and cheese. Moreover, important indications have been obtained toward the improvement of desaturation mechanisms in the bovine mammary gland. Our main findings concern the increased amounts of linoleic acid and CLA in milk and cheese from cows receiving dietary supplementation with Se, at the expense of SFA, reflecting improvements in the health functionality of these products, with interesting implications for humans. Additionally, the aromatic profile of dairy products was also positively affected by dietary Se intake. However, further sensorial analysis is needed to evaluate any variations in consumer acceptability.

\section{ACKNOWLEDGMENTS}

This work is part of the project "Innovazione della filiera bovina da latte in Abruzzo per produzioni lattiero-casearie ad elevato contenuto salutistico ed ecosostenibile," supported by a grant from Rural
Development Plan 2007-2013 MISURA 1.2.4 Regione Abruzzo (Italy). The authors are grateful to AN.SA. PE. Agricultural Cooperative (Raiano, Italy) for providing animals and facilities.

\section{REFERENCES}

AOAC. 1990. Official Methods of Analysis, Vol. 1. 15th ed. Association of Official Analytical Chemists (AOAC), Arlington, VA.

Aspila, P. 1991. Metabolism of selenite, selenomethionine and feedincorporated selenium in lactating goats and dairy cows. J. Agric. Sci. Finland 63:9-74.

Basiricò, L., P. Morera, D. Dipasquale, A. Tröscher, and U. Bernabucci. 2017. Comparison between conjugated linoleic acid and essential fatty acids in preventing oxidative stress in bovine mammary epithelial cells. J. Dairy Sci. 100:2299-2309.

Basiricò, L., P. Morera, D. Dipasquale, A. Tröscher, A. Serra, M. Mele, and U. Bernabucci. 2015. Conjugated linoleic acid isomers strongly improve the redox status of bovine mammary epithelial cells (BME-UV1). J. Dairy Sci. 98:7071-7082.

Bertuzzi, A. S., P. L. H. McSweeney, M. C. Rea, and K. N. Kilcawley. 2018. Detection of volatile compounds of cheese and their contribution to the flavor profile of surface-ripened cheese. Compr. Rev. Food Sci. Food Saf. 17:371-390.

Calamari, L., F. Petrera, and G. Bertin. 2010. Effects of either sodium selenite or Se yeast (Sc CNCM I-3060) supplementation on selenium status and milk characteristics in dairy cows. Livest. Sci. 128:154-165.

Castellani, F., A. Vitali, N. Bernardi, E. Marone, F. Palazzo, L. Grotta, and G. Martino. 2017. Dietary supplementation with dried olive pomace in dairy cows modifies the composition of fatty acids and the aromatic profile in milk and related cheese. J. Dairy Sci. 100:8658-8669.

Collins, Y. F., P. L. H. McSweeney, and M. G. Wilkinson. 2003. Lipolysis and free fatty acid catabolism in cheese: A review of current knowledge. Int. Dairy J. 13:841-866.

Cortinhas, C. S., B. G. Botaro, M. C. A. Sucupira, F. P. Rennó, and M. V. D. Santos. 2010. Antioxidant enzymes and somatic cell count in dairy cows fed with organic source of zinc, copper and selenium. Livest. Sci. 127:84-87.

Domagała, J., M. Sady, T. Grega, H. Pustkowiak, and A. Florkiewicz. 2010. The influence of cheese type and fat extraction method on the content of conjugated linoleic acid. J. Food Compos. Anal. $23: 238-243$.

Doreau, M., A. Meynadier, V. Fievez, and A. Ferlay. 2016. Ruminal metabolism of fatty acids: Modulation of polyunsaturated, conjugated, and trans fatty acids in meat and milk. Pages 521-542 in Handbook of Lipids in Human Function. AOCS Press, Urbana, IL.

Evans, M., J. Brown, and M. McIntosh. 2002. Isomer-specific effects of conjugated linoleic acid (CLA) on adiposity and lipid metabolism. J. Nutr. Biochem. 13:508-516.

Gerber, N., R. Brogioli, B. Hattendorf, M. R. L. Scheeder, C. Wenk, and D. Günther. 2009. Variability of selected trace elements of different meat cuts determined by ICP-MS and DRC-ICPMS. Animal 3:166-172.

Givens, D. I., R. Allison, B. Cottrill, and J. S. Blake. 2004. Enhancing the selenium content of bovine milk through alteration of the form and concentration of selenium in the diet of the dairy cow. J. Sci. Food Agric. 84:811-817.

Gresakova, L., K. Cobanova, and S. Faix. 2013. Selenium retention in lambs fed diets supplemented with selenium from inorganic or organic sources. Small Rumin. Res. 111:76-82.

Grotta, L., F. Castellani, F. Palazzo, M. N. Haouet, and G. Martino. 2017. Treatment optimisation and sample preparation for the evaluation of lipid oxidation in various meats through TBARs assays before analysis. Food Anal. Methods 10:1870-1880.

Ianni, A., G. Di Maio, P. Pittia, L. Grotta, G. Perpetuini, R. Tofalo, A. Cichelli, and G. Martino. 2019a. Chemical-nutritional quality and oxidative stability of milk and dairy products obtained from 
Friesian cows fed with a dietary supplementation of dried grape pomace. J. Sci. Food Agric. https://doi.org/10.1002/jsfa.9584.

Ianni, A., D. Innosa, C. Martino, F. Bennato, and G. Martino. 2019b. Compositional characteristics and aromatic profile of caciotta cheese obtained from Friesian cows fed with a dietary supplementation of dried grape pomace. J. Dairy Sci. https://doi.org/10 .3168/jds.2018-15590.

Kruze, J., A. Ceballos, H. Stryhn, A. Mella, R. Matamoros, P. A. Contreras, V. Leyan, and F. Wittwer. 2007. Somatic cell count in milk of selenium-supplemented dairy cows after an intramammary challenge with Staphylococcus aureus. J. Vet. Med. A Physiol. Pathol. Clin. Med. 54:478-483.

Ling, K., M. Henno, I. Jõudu, T. Püssa, H. Jaakson, M. Kass, D. Anton, and M. Ots. 2017. Selenium supplementation of diets of dairy cows to produce Se-enriched cheese. Int. Dairy J. 71:76-81.

Lock, A. L., B. A. Corl, D. M. Barbano, D. E. Bauman, and C. Ip. 2004. The anticarcinogenic effect of trans-11 18:1 is dependent on its conversion to cis-9, trans-11 CLA by $\Delta 9$-desaturase in rats. J. Nutr. 134:2698-2704.

Mele, M., G. Conte, B. Castiglioni, S. Chessa, N. P. P. Macciotta, A. Serra, A. Buccioni, G. Pagnacco, and P. Secchiari. 2007. Stearoylcoenzyme A desaturase gene polymorphism and milk fatty acid composition in Italian Holsteins. J. Dairy Sci. 90:4458-4465.

Miyazaki, M., and J. M. Ntambi. 2003. Role of stearoyl-coenzyme A desaturase in lipid metabolism. Prostaglandins Leukot. Essent. Fatty Acids 68:113-121.

Niimi, J., A. I. Eddy, A. R. Overington, P. Silcock, P. J. Bremer, and C. M. Delahunty. 2015. Sensory interactions between cheese aroma and taste. J. Sens. Stud. 30:247-257.

NRC. 2001. Nutrient Requirements of Dairy Cattle. Natl. Acad. Press, Washington, DC.

Pehrson, B., M. Knutsson, and M. Gyllensward. 1989. Glutathione peroxidase activity in heifers fed diets supplemented with organic and inorganic selenium compounds. Swed. J. Agric. Res. 19:53-56.

Pepper, M. P., M. Z. Vatamaniuk, X. Yan, C. A. Roneker, and X. G. Lei. 2011. Impacts of dietary selenium deficiency on metabolic phenotypes of diet-restricted GPX1-overexpressing mice. Antioxid. Redox Signal. 14:383-390.

Platt, I., L. G. Rao, and A. El-Sohemy. 2007. Isomer-specific effects of conjugated linoleic acid on mineralized bone nodule formation from human osteoblast-like cells. Exp. Biol. Med. (Maywood) 232:246-252.

Ran, L., X. Wu, X. Shen, K. Zhang, F. Ren, and K. Huang. 2010. Effects of selenium form on blood and milk selenium concentrations, milk component and milk fatty acid composition in dairy cows. J. Sci. Food Agric. 90:2214-2219.
Rayman, M. P. 2000. The importance of selenium to human health. Lancet 356:233-241.

Reffett, J. K., J. W. Spears, and T. T. Brown Jr.. 1988. Effect of dietary selenium on the primary and secondary immune response in calves challenged with infectious bovine rhinotracheitis virus. J. Nutr. 118:229-235.

Salman, S., A. Khol-Parisini, H. Schafft, M. Lahrssen-Wiederholt, H. W. Hulan, D. Dinse, and J. Zentek. 2009. The role of dietary selenium in bovine mammary gland health and immune function. Anim. Health Res. Rev. 10:21-34.

Smith, S. B. D. K. Lunt, K. Y. Chung, C. B. Choi, R. K. Tume, and M. Zembayashi. 2006. Adiposity, fatty acid composition, and delta-9 desaturase activity during growth in beef cattle. Anim. Sci J. $77: 478-486$

Song, H. J., I. Grant, D. Rotondo, I. Mohede, N. Sattar, S. D. Heys, and K. W. J. Wahle. 2005. Effect of CLA supplementation on immune function in young healthy volunteers. Eur. J. Clin. Nutr. 59:508-517.

Spears, J. W. 2003. Trace mineral bioavailability in ruminants. J. Nutr. 133:1506S-1509S.

Steinbrenner, H., B. Speckmann, and L. O. Klotz. 2016. Selenoproteins: Antioxidant selenoenzymes and beyond. Arch. Biochem. Biophys. 595:113-119.

Tofalo, R., M. Schirone, G. Fasoli, G. Perpetuini, F. Patrignani, A. C. Manetta, R. Lanciotti, A. Corsetti, G. Martino, and G. Suzzi. 2015. Influence of pig rennet on proteolysis, organic acids content and microbiota of Pecorino di Farindola, a traditional Italian ewe's raw milk cheese. Food Chem. 175:121-127.

Ulbricht, T. L. V., and D. A. T. Southgate. 1991. Coronary heart disease: Seven dietary factors. Lancet 338:985-992.

Van Ryssen, J. B. J., P. S. M. van Malsen, and F. Hartmann. 1998 Contribution of dietary sulfur to the interaction between selenium and copper in sheep. J. Agric. Sci. Camb. 130:107-114.

Van Soest, P. J., J. B. Robertson, and B. A. Lewis. 1991. Methods for dietary fiber, neutral detergent fiber, and nonstarch polysaccharides in relation to animal nutrition. J. Dairy Sci. 74:3583-3597.

Wang, C., Q. Liu, W. Z. Yang, Q. Dong, X. M. Yang, D. C. He, P. Zhang, K. H. Dong, and Y. X. Huang. 2009. Effects of selenium yeast on rumen fermentation, lactation performance and feed digestibilities in lactating dairy cows. Livest. Sci. 126:239-244.

Zimmerman, M. T., C. A. Bayse, R. R. Ramoutar, and J. L. Brumaghim. 2015. Sulphur and selenium antioxidants: Challenging radical scavenging mechanisms and developing structure-activity relationships based on metal binding. J. Inorg. Biochem. 145:3040. 